\title{
Efficient Hydrogen Production from Methanol Using A Single-Site
}

\section{$\mathrm{Pt}_{1} / \mathrm{CeO}_{2}$ Catalyst}

Lu-Ning Chen, ${ }^{1,2}$ Kai-Peng Hou, ${ }^{1,3}$ Yi-Sheng Liu,5 Zhi-Yuan Qi, ${ }^{1}$ Qi Zheng, ${ }^{1}$ Yi-

Hsien Lu, ${ }^{1}$ Jia-Yu Chen, ${ }^{2}$ Jeng-Lung Chen, ${ }^{6}$ Chih-Wen Pao, ${ }^{6}$ Shuo-Bo Wang, ${ }^{1}$

Yao-Bin Li,7 Shao-Hua Xie, ${ }^{8}$ Fu-Dong Liu, ${ }^{8}$ David Prendergast, ${ }^{4}$ Leonard E. Klebanoff, 9 Vitalie Stavila, ${ }^{9}$ Mark D. Allendorf, 9 Jinghua Guo, ${ }^{5}$ Lan-Sun Zheng, ${ }^{2} \mathrm{Ji}$ $\mathrm{Su}^{,}{ }^{*}, 1,4$ Gabor A. Somorjai ${ }^{*}, 1,3$

${ }^{1}$ Materials Sciences Division, 4 Molecular Foundry, Material Science Division, 5 Advanced Light Source, Lawrence Berkeley National Laboratory, Berkeley, California 94720, United States.

${ }^{2}$ State Key Laboratory of Physical Chemistry of Solid Surfaces, Collaborative Innovation Center of Chemistry for Energy Materials, and Department of Chemistry, College of Chemistry and Chemical Engineering, Xiamen University, Xiamen 361005, China.

3 Department of Chemistry, University of California-Berkeley, Berkeley, California 94720, United States.

${ }^{6}$ National Synchrotron Radiation Research Center, Science-Based Industrial Park Hsinchu 30076, Taiwan.

7 Institute of Urban Environment, Chinese Academy of Sciences, Xiamen 361021, China.

8 Department of Civil, Environmental, and Construction Engineering, Catalysis Cluster for Renewable Energy and Chemical Transformations (REACT), Nano-Science Technology Center (NSTC), University of Central Florida, Orlando, Florida, 32916, United States.

9 Sandia National Laboratories, Livermore, CA 94551, United States.

E-mail: jisu@lbl.gov; somorjai@berkeley.edu 


\section{Contents}

\begin{tabular}{|c|c|}
\hline 1. Experimental Section & S3-S4 \\
\hline 2. Supplementary results & S5-S8 \\
\hline Table S1. The best-fit EXAFS parameters of various samples. & S5 \\
\hline $\begin{array}{l}\text { Figure S1. (a) Low magnification TEM images, (b) XRD patterns and (c) } \mathrm{N}_{2} \text { adsorption- } \\
\text { desorption isotherms of } \mathrm{CeO}_{2} \text { nanorods. }\end{array}$ & S5 \\
\hline $\begin{array}{l}\text { Figure S2. Low magnification TEM images of (a) } 2.5 \mathrm{~nm} \text { Pt nanoparticles and (c) } 7.0 \mathrm{~nm} \\
\text { Pt nanoparticles and (b, d) their corresponding size distribution. }\end{array}$ & S5 \\
\hline Figure S3. XRD patterns of $\mathrm{Pt}_{1} / \mathrm{CeO}_{2}, 2.5 \mathrm{~nm} \mathrm{Pt} / \mathrm{CeO}_{2}$ and $7.0 \mathrm{~nm} \mathrm{Pt} / \mathrm{CeO}_{2}$. & S6 \\
\hline $\begin{array}{l}\text { Figure S4. Bright-field TEM images of } \mathrm{Pt}_{1} / \mathrm{CeO}_{2}, 2.5 \mathrm{~nm} \mathrm{Pt} / \mathrm{CeO}_{2} \text { and } 7.0 \mathrm{~nm} \mathrm{Pt} / \mathrm{CeO}_{2} \text {, } \\
\text { the particles with high contrast in white cycles are } \mathrm{Pt} \text { nanoparticles. }\end{array}$ & S6 \\
\hline $\begin{array}{l}\text { Figure S5. In situ DRIFTS of } \mathrm{CO} \text { adsorption and desorption on (a) } \mathrm{Pt}_{1} / \mathrm{CeO}_{2} \text {, (b) } 2.5 \mathrm{~nm} \\
\mathrm{Pt} / \mathrm{CeO}_{2} \text { and (c) } 7.0 \mathrm{~nm} \mathrm{Pt} / \mathrm{CeO}_{2} \text {. }\end{array}$ & S6 \\
\hline $\begin{array}{l}\text { Figure S6. (a) } k^{3} \text {-weighted Fourier transform EXAFS spectra of } \mathrm{Pt}_{1} / \mathrm{CeO}_{2} \text { before and after } \\
\text { long-time reaction, and bulk } \mathrm{Pt} \text { foil at the } \mathrm{Pt} \mathrm{L}_{3} \text {-edge. The red hollow points are fitting } \\
\text { results, (b) The normalized XANES spectra at the } \mathrm{Pt} \mathrm{L}_{3} \text {-edge of } \mathrm{Pt}_{1} / \mathrm{CeO}_{2} \text { before and after } \\
\text { long-time reaction and bulk Pt foil. }\end{array}$ & S7 \\
\hline $\begin{array}{l}\text { Figure S7. Turnover frequency (TOF) methanol convert to hydrogen and conversion of } \\
\text { methanol using } \mathrm{Pt}_{1} / \mathrm{CeO}_{2} \text { as catalyst under } 300{ }^{\circ} \mathrm{C} \text { with different methanol feeding rate. } \\
\text { Reaction condition: } 100 \mathrm{mg} \text { catalysts mixed with } 500 \mathrm{mg} \text { sand; Gas flow: } \mathrm{N}_{2} 30 \mathrm{ml} / \mathrm{min} \text {. }\end{array}$ & S7 \\
\hline $\begin{array}{l}\text { Figure S8. (a) The actual } \mathrm{Pt} \text { content of } \mathrm{Pt}_{1} / \mathrm{CeO}_{2} \text { catalysts with the Pt feeding amount } \\
\text { increase, (b) Turnover frequency (TOF) of hydrogen production from methanol in terms } \\
\text { of methanol conversion per } \mathrm{Pt} \text { site of different } \mathrm{Pt} \text { content } \mathrm{Pt}_{1} / \mathrm{CeO}_{2} \text { catalysts, the reaction } \\
\text { condition: } 100 \mathrm{mg} \text { catalysts mixed with } 500 \mathrm{mg} \text { sand; Gas flow: } \mathrm{N}_{2} 30 \mathrm{ml} / \mathrm{min} \text {; methanol } \\
\text { feed rate } 0.05 \mathrm{ml} / \mathrm{min} \text {. }\end{array}$ & S7 \\
\hline $\begin{array}{l}\text { Figure S9. XPS spectra and corresponding fitting curves of (a) } \mathrm{Pt} 4 \mathrm{f} \text { and (b) } \mathrm{Ce} 3 \mathrm{~d} \text { in the } \\
\mathrm{Pt}_{1} / \mathrm{CeO}_{2}, 2.5 \mathrm{~nm} \mathrm{Pt} / \mathrm{CeO}_{2} \text { and } 7.0 \mathrm{~nm} \mathrm{Pt} / \mathrm{CeO}_{2} \text {. }\end{array}$ & S8 \\
\hline $\begin{array}{l}\text { Figure S10. The mechanism of methanol dehydrogenation on single-site } \mathrm{Pt}_{1} / \mathrm{CeO}_{2} \\
\text { catalysts and } \mathrm{Pt} \text { nanoparticles loaded on } \mathrm{CeO}_{2} \text { catalysts. }\end{array}$ & S8 \\
\hline 3. References & S9 \\
\hline
\end{tabular}




\section{Experimental Section}

1.1. Chemicals and Materials. Cerium (III) nitrate hexahydrate $\left(\mathrm{Ce}\left(\mathrm{NO}_{3}\right)_{3} \cdot 6 \mathrm{H}_{2} \mathrm{O}, 99 \%\right)$, sodium hydroxide ( $\mathrm{NaOH}, 97 \%$ ), ascorbic acid (AA, $\mathrm{C}_{6} \mathrm{H}_{8} \mathrm{O}_{6}, 99 \%$ ), dihydrogen hexachloroplatinate (IV) hexahydrate $\left(\mathrm{H}_{2} \mathrm{PtCl}_{6} \cdot 6 \mathrm{H}_{2} \mathrm{O}, 99.9 \%\right)$, polyvinylpyrrolidone (PVP), methanol $\left(\mathrm{CH}_{4} \mathrm{O}, 99.9 \%\right)$, ethanol $\left(\mathrm{C}_{2} \mathrm{H}_{5} \mathrm{OH}, 99.8 \%\right)$, n-propanol $\left(\mathrm{C}_{3} \mathrm{H}_{7} \mathrm{OH}, 99.7 \%\right)$, isopropanol $\left(\mathrm{C}_{3} \mathrm{H}_{8} \mathrm{O}, 99.5 \%\right)$, butyl alcohol $\left(\mathrm{C}_{4} \mathrm{H}_{9} \mathrm{OH}, 99.5 \%\right)$, benzyl alcohol $\left(\mathrm{C}_{6} \mathrm{H}_{5} \mathrm{CH}_{2} \mathrm{OH}, 99.8 \%\right)$ and ethylene glycol $\left(\mathrm{C}_{2} \mathrm{H}_{6} \mathrm{O}\right.$, 99.8\%) were purchased from Sigma-Aldrich. All reagents were used without further purification.

1.2. Synthesis of porous $\mathrm{CeO}_{2}$. Porous $\mathrm{CeO}_{2}$ nanorods were synthesized according to previous reports. ${ }^{[\mathrm{S} 1]} 4 \mathrm{mmol} \mathrm{Ce}\left(\mathrm{NO}_{3}\right)_{3} \cdot 6 \mathrm{H}_{2} \mathrm{O}(1.736 \mathrm{~g})$ and $0.48 \mathrm{~mol} \mathrm{NaOH}(19.2 \mathrm{~g})$ were mixed and dissolved in $80 \mathrm{ml}$ distilled water. After stirred for $30 \mathrm{~min}$ at room temperature, the mixture solution was transferred to $100 \mathrm{ml}$ Teflon-lined stainless-steel autoclave and kept at $100{ }^{\circ} \mathrm{C}$ for $12 \mathrm{~h}$. The products were collected by centrifugation and washed with distilled water for several times. Finally, the products were dried in vacuum and calcinated at $400{ }^{\circ} \mathrm{C}$ in air for $1 \mathrm{~h} \cdot{ }^{[\mathrm{S} 1]}$

1.2. Synthesis of $\mathbf{P t}_{1} / \mathbf{C e O}_{2}$. First, $500 \mathrm{mg}$ porous $\mathrm{CeO}_{2}$ nanorods were dispersed in $175 \mathrm{ml}$ distilled water, then $1 \mathrm{mmol}$ ascorbic acid $(0.176 \mathrm{~g})$ was added in solution. After stirred at room temperature for $3 \mathrm{~h}$ the products were collected by centrifugation. After washed three times with distilled water, the products were dried in vacuum at $60{ }^{\circ} \mathrm{C}$, which donated as $\mathrm{CeO}_{2}-\mathrm{AA}$. Second, $140 \mathrm{mg}$ preprepared $\mathrm{CeO}_{2}$-AA were dispersed in $55 \mathrm{ml}$ distilled water and added $0.4 \mathrm{~mL}(10 \mathrm{mg} / \mathrm{mL}) \mathrm{H}_{2} \mathrm{PtCl}_{6}$ solution. After stirred for $3 \mathrm{~h}$ at room temperature, the products were collected by centrifugation. After washed with distilled water for three times, the products were dried up in vacuum at $30^{\circ} \mathrm{C}$. The dried products were calcinated at $300{ }^{\circ} \mathrm{C}$ in air for $1 \mathrm{~h}$ to remove the excess AA. ${ }^{[\mathrm{S} 2]}$

1.3. Synthesis of $2.5 \mathrm{~nm}$ Pt nanoparticles and $7.0 \mathrm{~nm}$ Pt nanoparticles. Pt nanoparticles with 2.5 $\mathrm{nm}$ and $7.0 \mathrm{~nm}$ were synthesized according to literature method. For $2.5 \mathrm{~nm}$ Pt nanoparticles, 133 $\mathrm{mg}$ PVP and $20 \mathrm{~mL}$ of $\mathrm{H}_{2} \mathrm{PtCl}_{6} \cdot 6 \mathrm{H}_{2} \mathrm{O}$ aqueous solution $(6.0 \mathrm{mM})$ were dissolved in $180 \mathrm{~mL}$ ethanol. Then mixture was refluxed for $3 \mathrm{~h}$. The solvent was evaporated, then the residue was dispersed in water and kept the concentration $5 \mathrm{mg} / \mathrm{mL}$. For $7.0 \mathrm{~nm}$ Pt nanoparticles, $3 \mathrm{~mL}$ ethylene glycol solution of PVP $(0.375 \mathrm{M})$ and ethylene glycol solution of $\mathrm{H}_{2} \mathrm{PtCl}_{6} \cdot 6 \mathrm{H}_{2} \mathrm{O}(0.0625 \mathrm{M})$ were alternately added to $2.5 \mathrm{~mL}$ boiling ethylene glycol every $30 \mathrm{~s}$. The mixture was further refluxed for $10 \mathrm{~min}$, the particles were collected by centrifugation and redispersed in water with concentration 5 $\mathrm{mg} / \mathrm{mL} \cdot{ }^{[\mathrm{S} 3]}$

1.4. Synthesis of $2.5 \mathrm{~nm} \mathrm{Pt} / \mathrm{CeO}_{2}$ and $7.0 \mathrm{~nm} \mathrm{Pt} / \mathrm{CeO}_{2} .500 \mathrm{mg} \mathrm{CeO}{ }_{2}$ was dispersed in $20 \mathrm{~mL}$ distilled water, then $1 \mathrm{~mL}$ of Pt nanoparticle aqueous solution $(5 \mathrm{mg} / \mathrm{mL})$ was added. After ultrasonic treatment for $1 \mathrm{~h}$ and stirring overnight, the particles were dried in vacuum at $100^{\circ} \mathrm{C}$. The products are named $2.5 \mathrm{~nm} \mathrm{Pt} / \mathrm{CeO}_{2}$ and $7.0 \mathrm{~nm} \mathrm{Pt} / \mathrm{CeO}_{2}$, respectively. The prepared $\mathrm{Pt} / \mathrm{CeO}_{2}$ composite was further processed with UV-ozone treatment to remove the capped PVP layer. ${ }^{[\mathrm{S} 4]}$

1.5. In Situ DRIFTS Study. Diffuse reflectance infrared Fourier transform spectroscopy (DRIFTS) was recorded on a Thermo Nicolet 6700 equipped with an in situ reaction chamber, which is covered by $\mathrm{KBr}$ filters. Before $\mathrm{CO}$ adsorption, the sample was heated to $150{ }^{\circ} \mathrm{C}$ in vacuum for $3 \mathrm{~h}$. After being cooled to room temperature, the chamber was purged with $40 \mathrm{~mL} \mathrm{~min}^{-1} \operatorname{Ar}(99.99 \%)$ gas flow for $20 \mathrm{~min}$ and then a background spectrum was taken. For the CO adsorption step, CO (99.99\%) gas was controlled by mass flow meters and fed at a flow rate of $30 \mathrm{~mL} \mathrm{~min}^{-1}$ for $15 \mathrm{~min}$. After CO adsorption, the gas flow was switched to $40 \mathrm{~mL} \mathrm{~min}^{-1} \mathrm{Ar}$, and the spectra were recorded in desired times.

1.6. Catalytic measurement of catalysts. The catalytic activity of $\mathrm{Pt}_{1} / \mathrm{CeO}_{2}, 2.5 \mathrm{~nm} \mathrm{Pt} / \mathrm{CeO}_{2}$ and 
$7.0 \mathrm{~nm} \mathrm{Pt} / \mathrm{CeO}_{2}$ toward hydrogen production from methanol was performed in a continuous flow reactor. In a typical catalytic measurement, $100 \mathrm{mg}$ catalyst was first mixed with $500 \mathrm{mg}$ white quartz (50-70 mesh particle size). The mixture was placed in a U-shape fixed-bed flow reactor. The feed of $30 \mathrm{~mL} / \mathrm{min} \mathrm{N}_{2}$ regulated by a mass flow controller to be at $1 \mathrm{~atm}$ and feed of $3 \mathrm{~mL} / \mathrm{h}$ methanol controlled by an injection pump were mixed together and directed towards catalysts. The temperature of bed was monitored by a K-type thermocouple controlled by a PID 679 controller. The products were analyzed on-line by HP 5890 GC (hayesep D column and hayesep Q column) equipped with TCD and FID detector. Besides, the liquid products were also collected and measured by NMR (AV-700).

The turnover frequency (TOF) calculation using the following equation:

$$
\text { Turnover Frequency (TOF) }=\frac{\text { Hydrogen Production }}{2 \times \text { Number of acitve Pt Sites } \times \text { time }}
$$

The production of hydrogenation was measured by GC equipped with TCD detector. $\mathrm{For} \mathrm{Pt}_{1} / \mathrm{CeO}_{2}$, the active Pt site are all the Pt element measured by ICP-OES, while for the $2.5 \mathrm{~nm} \mathrm{Pt} / \mathrm{CeO}_{2}$ and 7.0 $\mathrm{nm} \mathrm{Pt} / \mathrm{CeO}_{2}$ the number of active Pt sites are the exposed Pt atoms on the surface of Pt nanoparticles.

1.7. Characterization of samples. The morphology of products was observed by transmission electron microscope (TEM, JEOL 2100F) with an accelerating voltage of $200 \mathrm{kV}$. The high-angle annular dark-field scanning transmission electron microscopy (HAADF-STEM) and energydispersive X-ray spectroscopy (EDS) were performed with ThemIS microscope at $300 \mathrm{kV}$. operated at $300 \mathrm{kV}$. The composition of products was determined by powder X-ray diffraction (XRD) on a Rigaku D/max X-ray diffractometer ( $\mathrm{Cu} \mathrm{Ka}$ radiation, $0.15418 \mathrm{~nm})$. X-ray photoelectron spectroscopy (XPS) was measured by K-Alpha Plus XPS/UPS. The actual amounts of Pt of catalysts were confirmed by elemental analysis using inductively coupled plasma optical emission spectroscopy (ICP-OES, Perkin Elmer 5300 DV optical emission ICP with auto sampler). Volumetric adsorption isotherms for $\mathrm{N}_{2}$ of $\mathrm{CeO}_{2}$ were obtained using a Micromeritics ASAP 2020 gas adsorption analyzer.

1.8 X-ray absorption spectroscopy (XAS) measurements. The measurements of Pt $\boldsymbol{L}_{3}$-edge XAS spectra including X-ray absorption near edge structure (XANES) and extended X-ray absorption fine structure (EXAFS) were performed at the TPS 44A beamline of the National Synchrotron Radiation Research Center (NSRRC) Taiwan. The data were collected in fluorescence mode by using 7-element silicon drift detector and the standard Pt-foil was used as reference for the energy calibration. The data were processed according to standard procedures using Demeter program package ${ }^{[\mathrm{S5}]}$. 


\section{Supplementary Results}

\begin{tabular}{|c|c|c|c|c|c|c|}
\hline Sample & Scattering path & $\Delta R$ & $\mathrm{~N}$ & $\mathrm{R}(\AA)$ & $\sigma^{2}\left(\AA^{2}\right)$ & $\mathrm{R}_{\mathrm{f}}$ \\
\hline $\mathrm{Pt}$ foil & Pt-Pt bond & $2.28 \sim 3.13 \AA$ & 12 & 2.76 & 0.005 & 0.002 \\
\hline $\mathrm{Pt}_{1} / \mathrm{CeO}_{2}$ & Pt-O bond & $1.18 \sim 2.09 \AA$ & 6 & 1.99 & 0.004 & 0.002 \\
\hline $\begin{array}{c}\mathrm{Pt}_{1} / \mathrm{CeO}_{2} \\
(\text { after reaction) }\end{array}$ & Pt-O bond & $1.18 \sim 2.09 \AA$ & 6 & 1.99 & 0.002 & 0.004 \\
\hline
\end{tabular}

Table S1. The best-fit EXAFS parameters of various samples, where the curve fitting was conducted in R-space with the fitting range $(\Delta \mathrm{R})$ and the $\mathrm{R}$-factor $\left(\mathrm{R}_{\mathrm{f}}\right)$ of fit indicated in the table, where $\mathrm{N}$ is coordination number, $\mathrm{R}$ is distance between absorber and backscatter atoms, $\sigma^{2}$ is Debye-Waller factor value, $\Delta \mathrm{R}$ is data range for fitting in $\mathrm{R}$-space, $\mathrm{R}_{\mathrm{f}}$ is $\mathrm{R}$-factor characterizing the goodness of fit. Error bounds (accuracies) characterizing the structural parameters obtained by EXAFS data analysis are estimated to be as follows: $\mathrm{N}, \pm 20 \%$;, $\pm 1 \%$; and $\sigma 2, \pm 20 \%$.
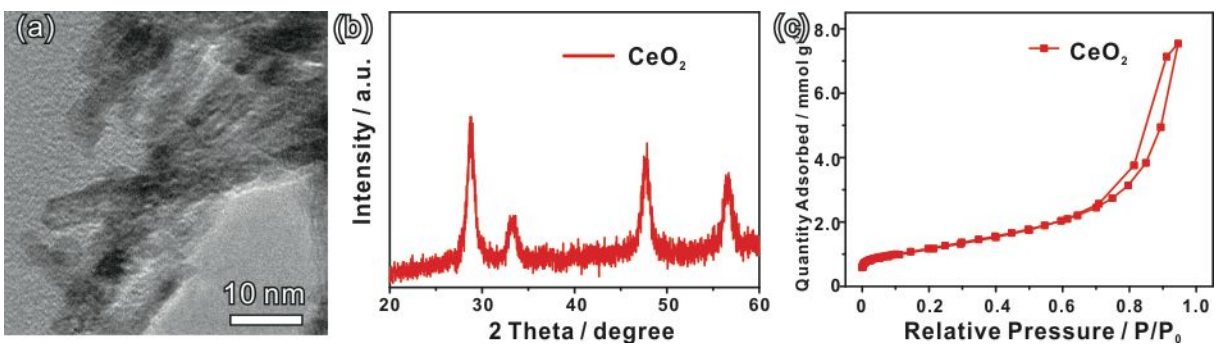

Figure S1. (a) Low magnification TEM images, (b) XRD patterns and (c) $\mathrm{N}_{2}$ adsorption-desorption isotherms of $\mathrm{CeO}_{2}$ nanorod.
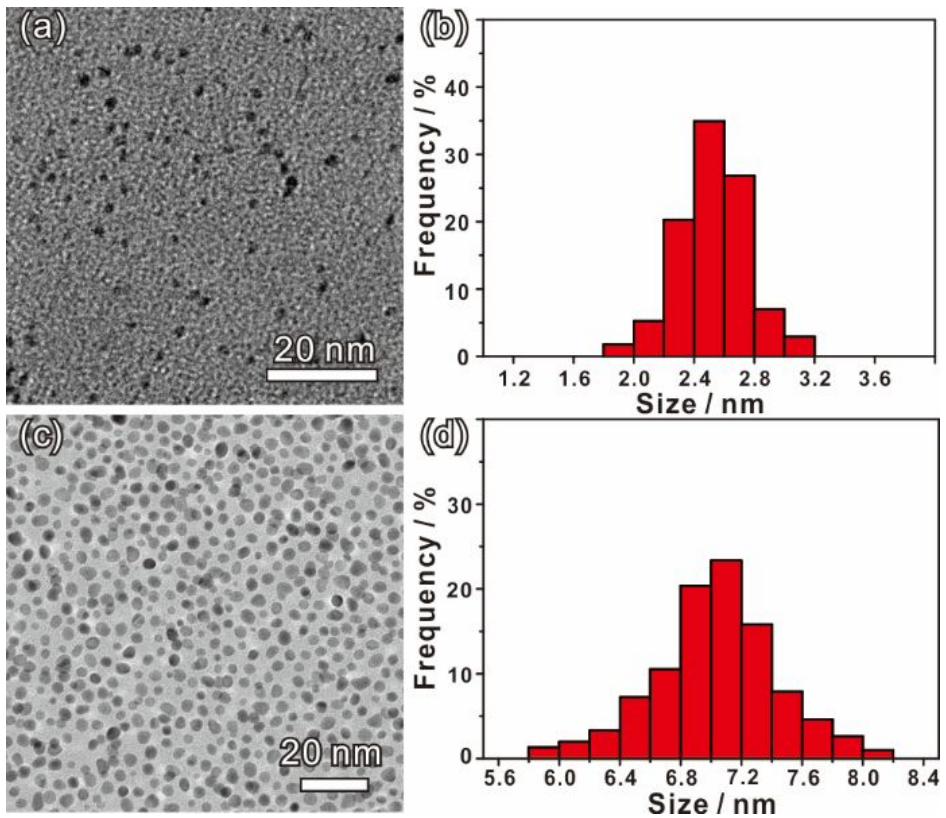

Figure S2. Low magnification TEM images of (a) $2.5 \mathrm{~nm}$ Pt nanoparticles and (c)7.0 nm Pt nanoparticles and $(b, d)$ their corresponding size distribution. 


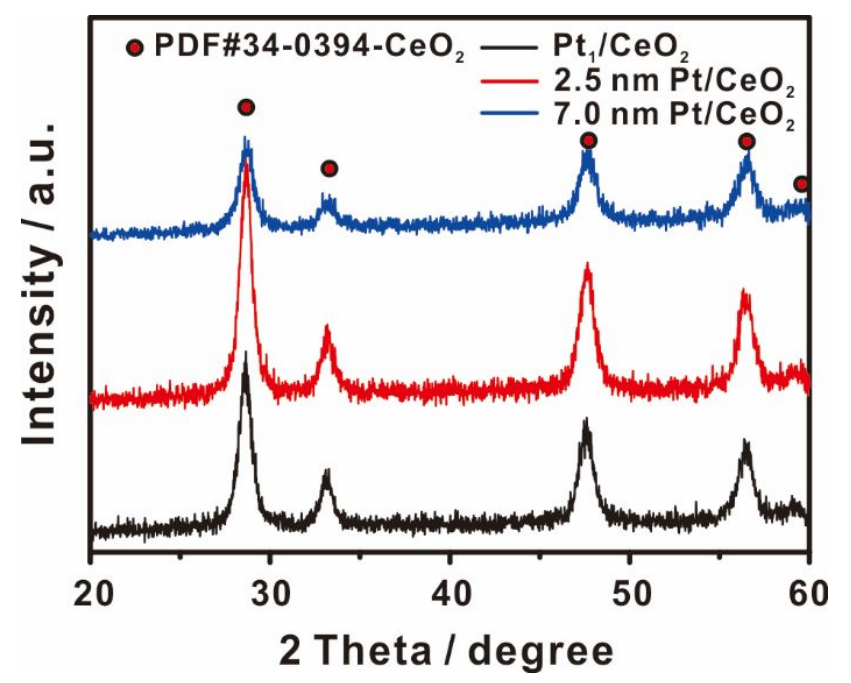

Figure S3. XRD patterns of $\mathrm{Pt}_{1} / \mathrm{CeO}_{2}, 2.5 \mathrm{~nm} \mathrm{Pt} / \mathrm{CeO}_{2}$ and $7.0 \mathrm{~nm} \mathrm{Pt} / \mathrm{CeO}_{2}$.
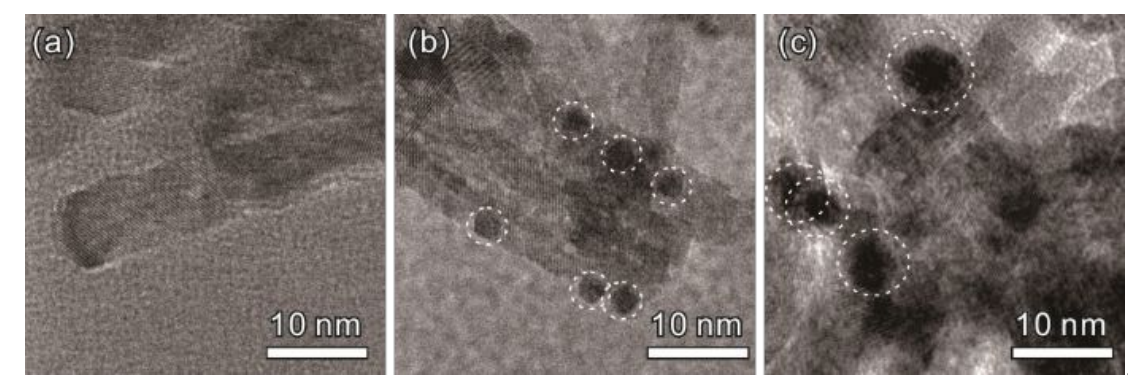

Figure S4. Bright-field TEM images of $\mathrm{Pt}_{1} / \mathrm{CeO}_{2}, 2.5 \mathrm{~nm} \mathrm{Pt} / \mathrm{CeO}_{2}$ and $7.0 \mathrm{~nm} \mathrm{Pt} / \mathrm{CeO}_{2}$, the particles with high contrast in white cycles are Pt nanoparticles.
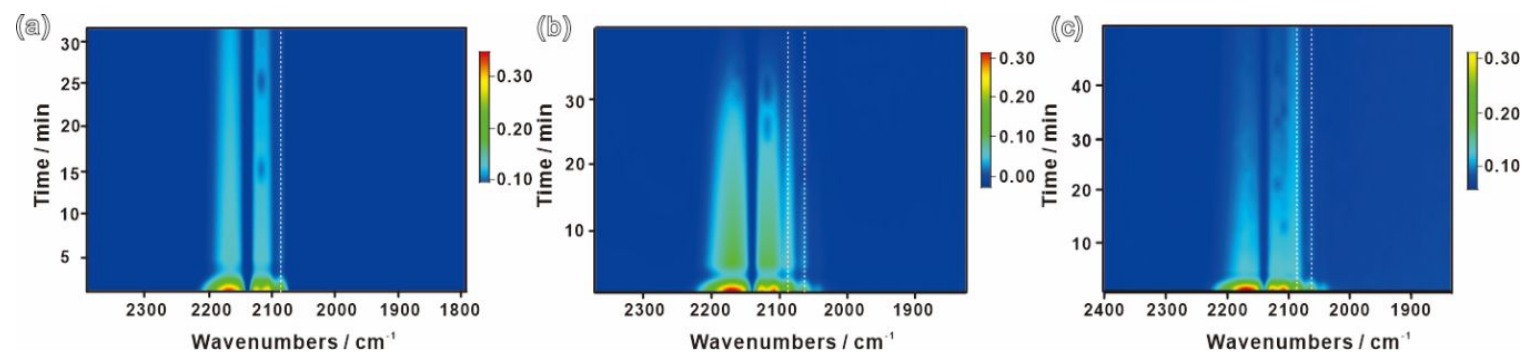

Figure S5. In situ DRIFTS of CO adsorption and desorption on (a) $\mathrm{Pt}_{1} / \mathrm{CeO}_{2}$, (b) $2.5 \mathrm{~nm} \mathrm{Pt} / \mathrm{CeO}_{2}$ and (c) $7.0 \mathrm{~nm} \mathrm{Pt} / \mathrm{CeO}_{2}$. 

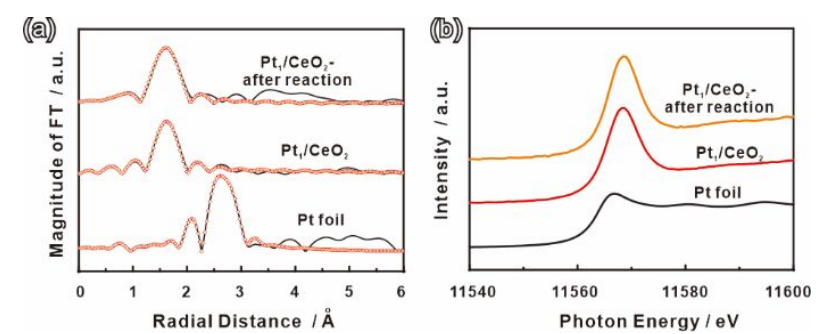

Figure S6. (a) $k^{3}$-weighted Fourier transform EXAFS spectra of $\mathrm{Pt}_{1} / \mathrm{CeO}_{2}$ before and after longtime reaction, and bulk $\mathrm{Pt}$ foil at the $\mathrm{Pt}_{\mathrm{L}_{3}}$-edge. The red hollow points are fitting results, (b) The normalized XANES spectra at the $\mathrm{Pt}_{3}$-edge of $\mathrm{Pt}_{1} / \mathrm{CeO}_{2}$ before and after long-time reaction and bulk Pt foil.

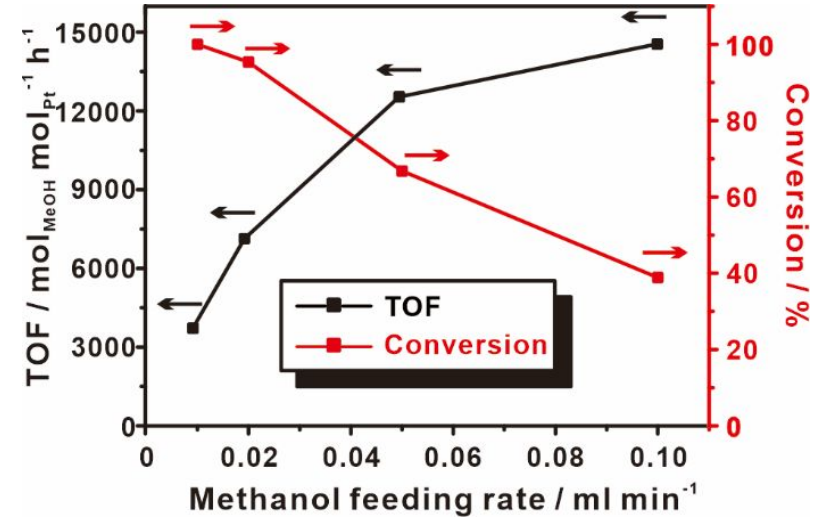

Figure S7. Turnover frequency (TOF) methanol converse to hydrogen and conversion of methanol using $\mathrm{Pt}_{1} / \mathrm{CeO}_{2}$ as catalyst under $300{ }^{\circ} \mathrm{C}$ with different methanol feeding rate. Reaction condition: $100 \mathrm{mg}$ catalysts mixed with $500 \mathrm{mg}$ sand; Gas flow: $\mathrm{N}_{2} 30 \mathrm{ml} / \mathrm{min}$.
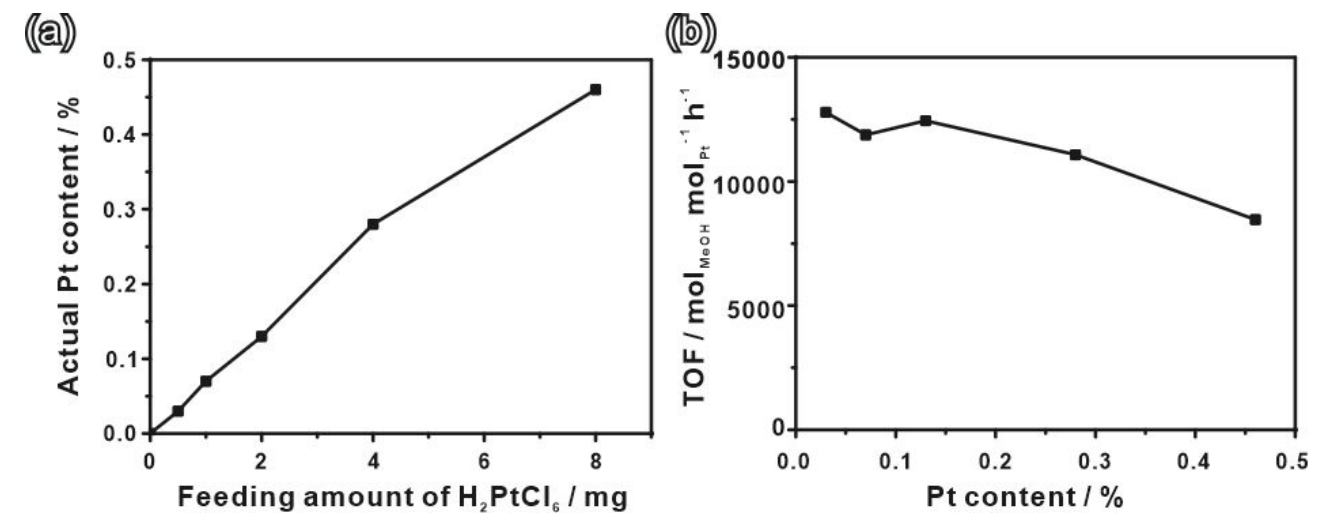

Figure S8. (a) the actual Pt content of $\mathrm{Pt}_{1} / \mathrm{CeO}_{2}$ catalysts with the Pt feeding amount increase, (b) Turnover frequency (TOF) of hydrogen production from methanol in terms of methanol conversion per Pt site of different $\mathrm{Pt}$ content $\mathrm{Pt}_{1} / \mathrm{CeO}_{2}$ catalysts, the reaction condition: $100 \mathrm{mg}$ catalysts mixed with $500 \mathrm{mg}$ sand; Gas flow: $\mathrm{N}_{2} 30 \mathrm{ml} / \mathrm{min}$; methanol feed rate $0.05 \mathrm{ml} / \mathrm{min}$. 

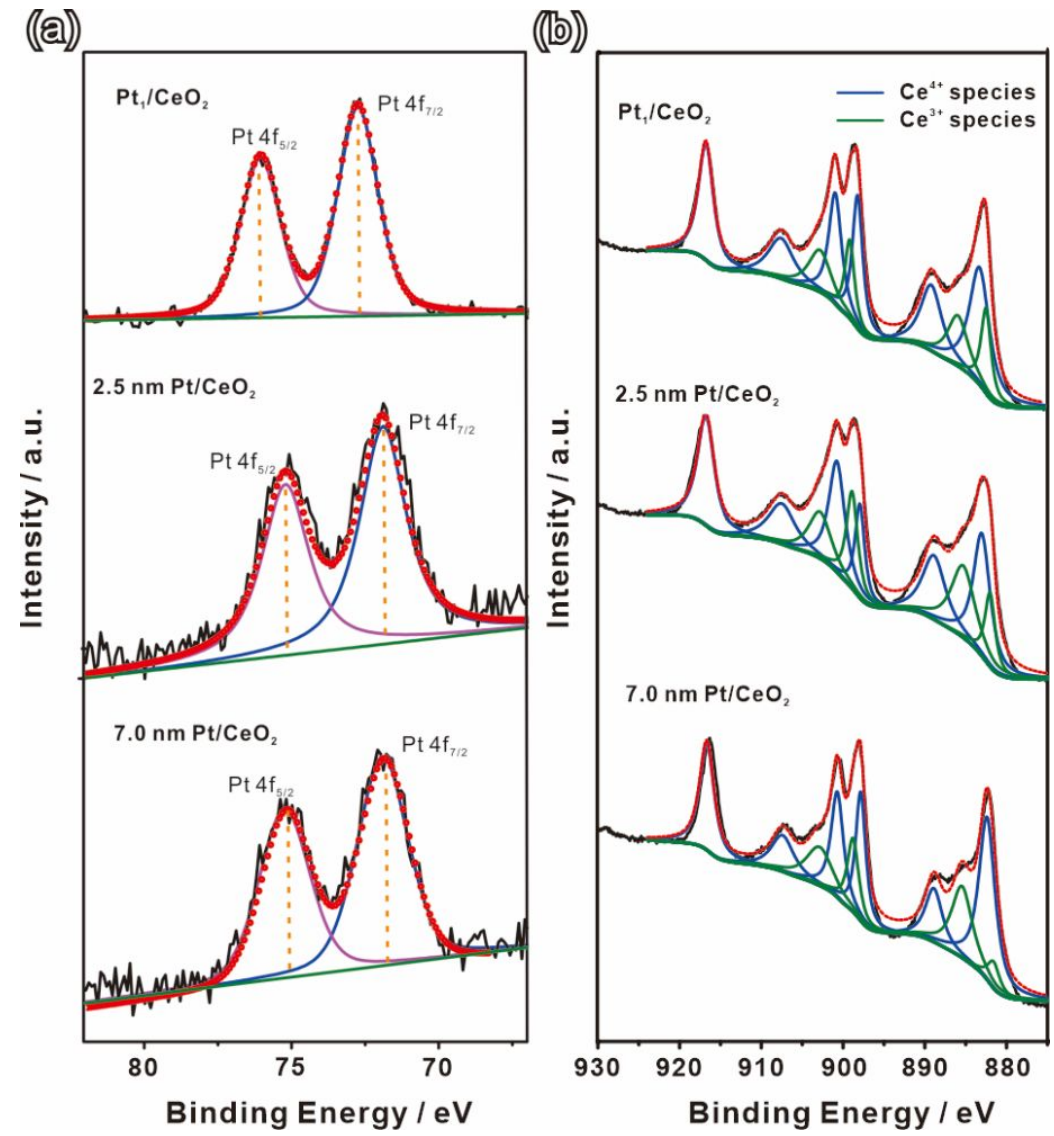

Figure S9. XPS spectra and corresponding fitting curves of (a) $\mathrm{Pt} 4 \mathrm{f}$ and (b) $\mathrm{Ce} 3 \mathrm{~d}$ in the $\mathrm{Pt}_{1} / \mathrm{CeO}_{2}$, $2.5 \mathrm{~nm} \mathrm{Pt} / \mathrm{CeO}_{2}$ and $7.0 \mathrm{~nm} \mathrm{Pt} / \mathrm{CeO}_{2}$.
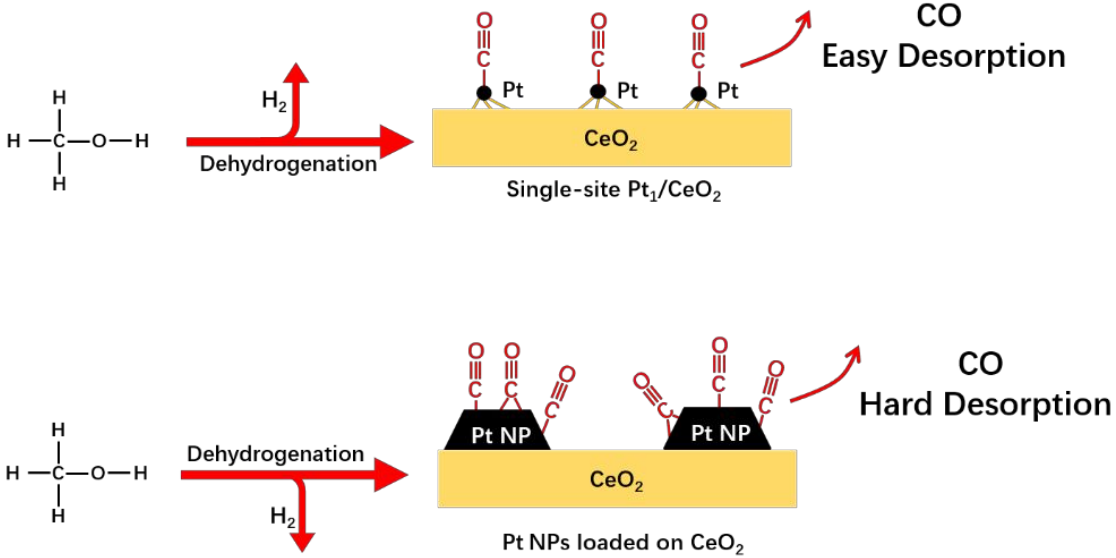

Figure S10. The proposed mechanism of methanol dehydrogenation on single-site $\mathrm{Pt}_{1} / \mathrm{CeO}_{2}$ catalysts and $\mathrm{Pt}$ nanoparticles loaded on $\mathrm{CeO}_{2}$ catalysts. 


\section{References}

(S1) Mai, H. X.; Sun, L. D.; Zhang, Y. W.; Si, R.; Feng, W.; Zhang, H. P.; Liu, H. C.; Yan, C. H. J. Phys. Chem. B 2005, 109, 24380.

(S2) Chen, J.; Wanyan, Y.; Zeng, J.; Fang, H.; Li, Z.; Dong, Y.; Qin, R.; Wu, C.; Liu, D.; Wang, M.; Kuang, Q.; Xie, Z.; Zheng, L. ACS Sustainable Chem. Eng. 2018, 6, 14054.

(S3) Rioux, R. M.; Song, H.; Hoefelmeyer, J. D.; Yang, P.; Somorjai, G. A. J. Phys. Chem. B 2005, 109, 2192.

(S4) Aliaga, C.; Park, J. Y.; Yamada, Y.; Lee, H. S.; Tsung, C. K.; Yang, P. D.; Somorjai, G. A. J. Phys. Chem. C 2009, 113, 6150.

(S5) Ravel, B.; Newville, M. J. Synchrotron Radiat. 2005, 12, 537. 